\title{
Empowerment, Expectations, Priorities and Attitudes Toward Development
}

\author{
1,2Asnarulkhadi Abu Samah \\ 1Hamizah Sahharon \\ 1Sulaiman Yassin \\ 3Bahaman Abu Samah \\ ${ }^{1}$ Hayrol Azril Mohamed Shaffril
}

1'Institute for Social Science Studies, Universiti Putra Malaysia

${ }^{2}$ Faculty of Human Ecology, Universiti Putra Malaysia

${ }^{3}$ Faculty of Educational Studies, Universiti Putra Malaysia

\section{Doi:10.5901/mjss.2015.v6n6s4p469}

\begin{abstract}
The main objective of this study is to examine the empowerment, expectation, priorities and attitudes toward development among rural community in Malaysia. This study is quantitative in nature and a total of 900 respondents from three states in Peninsular Malaysia were involved. This study has found that the rural communities were very well aware of the needs for local development and exhibited high expectations on its life-changing outcomes. The findings showed high rural community's involvement in decision making and self-accomplished. A number of discussions had been placed and it is a hope that it can assist the concern parties to further develop the rural community in Malaysia.
\end{abstract}

Keywords: Rural development, community empowerment, community building.

\section{What is the Pace of Rural Development within Malaysia?}

Malaysia is one of the fastest Third world developing countries that undergo several transformation programmes to improve the well-being of its rural communities after claiming independence. From infrastructure to facilities and support services, the Malaysian government has been disseminating development programs to ensure the quality of rural lives (Ngah, 2010). From 1991 to 2000 and since the millennium to 2010, the government has been trying to improve the quality of life by expanding infrastructure and amenities to remote areas while striving to eradicate poverty. With Vision 2020 in mind, the ruling party aimed to have growth with equity among Malaysians, subsequently building a resilient and a competitive nation.

Rural development is slow compared to the urban development in Malaysia. Rural region still undergo poor communication infrastructures, low levels of knowledge and limited incomes. These phenomena have put the rural people in a disadvantaged position, resulting in a huge development divide between the urban and the rural.

\section{Diffusion of Innovations and Community Building}

In a community led development approach, social and cultural capital exploitation emerged as an endogenous development. Community led development acts on local impulses and substantiated from local resources, which in turn profits the local economy and local product values (Terluin, 2003). The bottom-up approach of capacity building emphasized by Murray and Dunn (1995) focuses on reinforcing of self- help capacity of local entities, a necessity to deal with conflicts, provide better regulations, delivering employment, reinforce leadership, vision sharing, establishing and sustaining the local economic development (Terluin, 2003; Nakrosis, 2014). Capacity building derived from community action, participation and empowerment through sustained community collaboration to identify their priorities and needs for local development. To enhance their quality of life, the local entities should possess adaptation capability to recognize the key problems to improving the wellbeing to their community.

In terms of socio-economic status, Rogers claimed that earlier adopters tended to have more education, higher 
level of literacy, upward social mobility, larger farms, commercial rather than a subsistence economic orientation, and more favourable attitudes towards credit, and practice specialized operations more often than late adopters (MacVaugh \& Schiavone, 2010). In the ecology of rural communities, social conditions that hold the cultural and hierarchies plays an important role in influencing their susceptibility to be diffused to innovations. As stated by MacVaugh and Schiavone (2010), the community leader's opinion matters a lot, therefore it is essential to ensure that opinion leaders are the adopters since they play a critical role in diffusing local innovations. The community's low level of knowledge causes them to lack up-to-date information and skills (Belay \& Abebaw, 2004), hence slow adopters were deprived to market conditions and technologies which could benefit their products in order to reach the market demand (Sianipar et al., 2013).

The provision of online learning materials and courses will add value in terms of socio-economically, educationally and the livelihood to the marginalized communities. As the vision of the National Strategic Framework is to bridge the digital and mental divide among those at the rural and urban areas and those who haves and those who haves not there is an immediate need to educate the community with the appropriate digital content. Rural entrepreneur's knowledge, motivations and values matters greatly to support changes (Knickel et al., 2009). The community's willingness to adjust their practices and the inadequate advisory services from the implementers to educate the rural entrepreneur to acknowledge the importance of innovations were emphasized by many community building studies.

\section{Sustaining Development and Rural Empowerment}

Rural empowerment on the other hand seems by far outreaching for rural Malaysia, there are not many studies done on accessing or evaluating rural empowerment in Malaysia. The government's objectives to uplift the quality of life among the rural population would not be possible without the community's participation (Putnam, 2000). By means of third-world transformation programmes, the rural communities should as well be the patron in sustaining rural development. Sianipar et al. (2013) claimed that the implementers should not only play the role of contractors but also serve to train local in order to sustain the result. This principle is known as the empowerment process which requires a full support from the community's participation by allocating each members of community in development activity's engagement within the community by assigning the designated roles to the trustees (Samah and Aref, 2011).

To have a sustainable development, the rural community should be able to stand on their own to meet their present needs and empowered to overcome their future community's problem without the help of the implementers (WCED, 1987; Ferguson, 2010; Kasmel et al., 2011). Whilst the continuous attempt to emphasize local empowerment, the decision making flow must be done from the inside-outside procedure; from local communities to external authorities. Outsiders must first understand the ecology of the local community to reach the designated social power to empower them (Speer \& Hughey, 1995). Subsequently they will have to educate the locals to be well aware of the importance of local development, its benefits and be involve in every decision making process during activities which involves local development.

Previously it was mentioned that the locals needed to be exposed to knowledge capitalization. As mentioned by Sianipar et al. (2013), the main entity in developing countries when carrying out community empowerment projects are community members themselves, followed by university researchers and the government. Once the community's awareness was highlighted through community development then their increase of knowledge will sustain the development implemented. Accordingly the ongoing transformation progress beyond the sustained development and independence from community members to the outsiders is the proof of an empowered community. However, Sianipar et al. (2013) found in their study that development cannot be sustained due to community's low level of empowerment, thus suggesting the introduction of appropriate technology to fill the knowledge gap. Therefore this study have conducted a survey on 900 participants regarding their level of awareness, involvement, decision making, independence, expectations, perceptions and attitudes towards local development.

\section{Methodology}

As the study involves a big number of respondents, therefore, using the quantitative method is considered as the channel to assist the researchers to achieve the determined objective. A developed questionnaire was used as the main tool in collecting the data. The questionnaire was developed based on reviews of literature and past questions and then was further developed via a series of instrument development workshops. Then, the questionnaire was pre-tested and the resulted Cronbach alpha value was exceeded the recommended alpha value of .700. Subsequently, the actual data collection took places for six months and it involves a total of 900 respondents from three states (Pahang, Negeri 
Sembilan and Johor). Simple random sampling was the main sampling technique used in selecting the respondents. The researchers chose to perform simple random sampling as it can provide a sample that is highly representative of the population being studied, assuming that there is limited missing data. The data collection process was assisted by trained and experienced enumerators and the main data collection technique used was survey. The research team members was also involved to monitor the data collection process. Data collected then was analysed using SPSS. In order to achieve the objective of the study, descriptive analyses such as frequency, percentage, mean score and standard deviation were performed.

\section{The Community's Level of Awareness, Involvement, Decision Making and Independence on Local Development}

Despite many rural transformation programmes introduced on rural communities in Malaysia, there were few data available on the statistics of the evaluation of programme outcomes. Specifically regarding the rural participation, there were few statistics to show the success of a project's aftermath although many studies were carried out on the effectiveness of a project's achievement in the process (Ngah, 2010).

According to Table 1, the rural communities studied had a moderately high level of awareness $(M=4.40)$ for development. This result somewhat displayed how well aware these rural communities were regarding their local development, as suggested by Speer \& Hughey (1995) and MacVaugh and Schiavone (2010), the community leader's opinion matters a lot when diffusing local innovations. Therefore, it shows that the locals were well aware of its benefits in terms of uplifting their socio-economic status.

Table 1: Overall mean score for community's awareness

\begin{tabular}{lcccc}
\hline Level & Frequency & Percentage & Mean & SD* $^{*}$ \\
\hline \hline Awareness & & & 4.40 & .534 \\
Low $(1.00-2.33)$ & 0 & 0 & & \\
Moderate (2.34-3.67) & 54 & 6.0 & & \\
High (3.68-5.00) & 846 & 94.0 & & \\
*SD = Standard Deviation & & & &
\end{tabular}

*SD = Standard Deviation

Table 2 illustrates that the rural communities were highly aware that without ambition for self-success there will be no changes in their village's development, the essential of transformation in economy or irrigation of a community and temporarily being distressed during the initial stage of changes were normal. However, they had an insight that the development of a community discerning solely on government and not on themselves. They partially think themselves being responsible for their own community's development, thus they hardly gave any thoughts on the progress of various efforts, which could possibly empower them to sustain their own development. Just as Terluin (2003) conveyed in his community led development study, the locals have self-ambition in establishing a shared vision in accomplishing improvement and their self-help capacity is eminently portrayed.

Table 2: Overall mean score on items of community's awareness

\begin{tabular}{lr}
\hline Awareness & Mean SD* \\
\hline \hline I think that if we do not have any ambition for self-success, changes will never happen & 4.43 .591 \\
I think that transformation (such as the economy or irrigation) is essential for the welfare of a community & 4.42 .559 \\
At the initial stage (process) of changes, one will feel distressed, but it is only temporary & 4.42 .594 \\
Involvement (participation) in a project / activity (progress) can promote self and family improvement - thus & 4.41 .579 \\
enhancing living standards & 4.35 .642 \\
The development of self, family or community vigorously rely on one self, rather than government support alone & 4.35 .644 \\
\hline Actually there are a lot more efforts or development initiatives (progress) which can be realized in this area
\end{tabular}

*SD = Standard Deviation

According to Table 3, the rural communities studied had a moderately high level of involvement $(M=3.83)$ in development programs. 
Table 3: Overall mean score for community's involvement

\begin{tabular}{lcccc}
\hline Level & Frequency & Percentage & Mean & SD $^{*}$ \\
\hline \hline Involvement & & & 3.83 & .732 \\
Low $(1.00-2.33)$ & 37 & 4.1 & & \\
Moderate $(2.34-3.67)$ & 262 & 29.1 & & \\
High $(3.68-5.00)$ & 601 & 66.8 & & \\
\hline
\end{tabular}

*SD = Standard Deviation

Table 4 demonstrates that the rural communities were highly involved in development programs on their own will and hardly miss participating in development programs carried out by their village. This quality emphasized their willingness to support changes and values development greatly, which is a good quality for community building (Knickel et al., 2009). However, they were only moderately willing to tolerate and sacrifice personal interests and properties for the success of local development. These statements depict the low level of knowledge the locals have regarding community building. Hence, without proper knowledge as conveyed by Belay and Abebaw (2004) in their study, these people lack up-to-date information and skills and missed the highlight to be involve in every decision making process during activities. As Sianipar et al. (2013) have said, community themselves are important entities to ensure their own development progress but being slow adopters, like Roger's theory, the locals were deprived to market conditions and technologies that could benefit them, which was why they still rely heavily on the government.

Table 4: Overall mean score on items of community's involvement

\begin{tabular}{lcc}
\hline Involvement & Mean & SD* $^{*}$ \\
\hline \hline My involvement in activities / projects were not influenced by anyone, it was my own desire & 4.01 & .739 \\
So far, I have never missed participating in activities or development programs carried out by this village & 3.94 & .817 \\
I have probably participated in more than 50\% of the development activities organized by the government & 3.90 & .837 \\
agency in this village & 3.89 & .845 \\
In the future, I do not want to miss (want to participate) any projects / activities (progress) & 3.71 \\
I am ready to leave work now, if a new project promises a much worthy income & .940 \\
I am willing to sacrifice personal interests for the sake of the success of local development & .902 \\
I can tolerate, if necessary, in order to develop this village (if it involves the acquisition of land) & 3.66 & .956 \\
\hline
\end{tabular}

*SD = Standard Deviation

According to Table 5, the rural communities studied had a moderate level of decision making $(M=3.58)$ in local development affairs.

Table 5: Overall mean score for community's decision making

\begin{tabular}{lcccc}
\hline Level & Frequency & Percentage & Mean & $\mathrm{SD}^{*}$ \\
\hline \hline Decision making $(\mathrm{n}=885)$ & & & 3.58 & .980 \\
Low $(1.00-2.33)$ & 110 & 12.4 & & \\
Moderate $(2.34-3.67)$ & 281 & 31.8 & & \\
High $(3.68-5.00)$ & 494 & 55.8 & & \\
*SD = Standard Deviation & & & &
\end{tabular}

Table 6 exhibits that the rural communities were moderately involved in attending and voicing out their opinions during meetings on local development and regarding affairs of the community. Although the mean score was not as low, but compared to the previous statements regarding their awareness in self-ambition and their perception in activities involvement, in real situation here where they actually voice out their opinion and views the mean scores were quite low. It proves that the Malaysian rural participation level still could not reach the empowerment level. These findings were similar to Sianipar et al.'s (2013) study, which found that development cannot be sustained due to community's low level of empowerment. 
Table 6: Overall mean score on items of community's decision making

\begin{tabular}{lc}
\hline Decision making & Mean SD* \\
\hline \hline From last year experience, if I was informed or received any information, I will attend any meetings or \\
discussions to develop this village
\end{tabular}

The corresponding figures in Table 7 displayed the rural community's high level of independence $(M=3.94)$ in local development affairs.

Table 7: Overall mean score for community's independence

\begin{tabular}{lcccc}
\hline Level & Frequency & Percentage & Mean & SD $^{*}$ \\
\hline \hline Independence $(n=894)$ & & & 3.94 & .881 \\
Low $(1.00-2.33)$ & 52 & 5.8 & & \\
Moderate $(2.34-3.67)$ & 180 & 20.1 & & \\
High $(3.68-5.00)$ & 662 & 74.1 & & \\
${ }^{*}$ SD $=$ Standard Deviation & & & &
\end{tabular}

Table 8 revealed the rural communities were morally independent in accomplishing their own efforts to transform their own lives and attend their own needs without depending too much on the Malaysian government's assistance. This highlights their will to accomplish their own local needs and future development; however, they lack knowledge on how to sustain the development on their own. On the good side, this could signal a will for a bottom-up approach as explained by Murray and Dunn (1995) where the locals were the major entities in making decisions in dealing with local conflicts. All that is left now is for the implementers or government agencies such as university researchers and government officials to educate these people and to provide better regulations and infuse leadership quality within the locals for the sake of their future.

Table 8: Overall mean score on items of community's independence

\begin{tabular}{lcc}
\hline Independent & Mean & SD* $^{*}$ \\
\hline \hline My life's principle - I will try to accomplish every efforts to develop (life transformation) myself and my family & 4.02 & .871 \\
In my opinion, all this time I can accomplish on my own to meet the needs of my life (and family) & 3.98 & .900 \\
So far, I do not depend on governments' assistance in order to get what I desire & 3.83 & 1.03 \\
\hline
\end{tabular}

${ }^{*} \mathrm{SD}=$ Standard Deviation

\section{Expectations, Priorities and Attitude Towards Local Development}

The corresponding figures in Table 9 unveiled the rural community's high level of expectation $(M=4.38)$ for local development.

Table 9: Overall mean score for community's expectations

\begin{tabular}{lcccc}
\hline Level & Frequency & Percentage & Mean & $\mathrm{SD}^{*}$ \\
\hline \hline Expectations & & & 4.38 & .600 \\
Low $(1.00-2.33)$ & 3 & 0.3 & & \\
Moderate $(2.34-3.67)$ & 52 & 5.8 & & \\
High $(3.68-5.00)$ & 845 & 93.9 & & \\
\hline * & &
\end{tabular}

${ }^{*} \mathrm{SD}=$ Standard Deviation

Table 10 demonstrated the rural communities highly expected the local development to change their lives in terms of income generation, job opportunities and their surroundings. These people anticipated for a brighter future from local development implemented by the government with the help of community members and village officials. 
Table 10: Overall mean score on items of community's expectations

\begin{tabular}{lcc}
\hline Expectations & Mean & SD* $^{*}$ \\
\hline \hline Local development has the potential to change the lives of a community & 4.41 & .603 \\
Local development can develop surrounding villages & 4.40 & .605 \\
Local development provide opportunities for the community to learn something new & 4.39 & .607 \\
Local development can generate the community's income & 4.38 & .622 \\
Local development can provide jobs & 4.37 & .648 \\
\hline *SD = Standard Deviation & &
\end{tabular}

${ }^{*} \mathrm{SD}=$ Standard Deviation

The corresponding figures in Table 11 showed the community member's high level of perceptions ( $M=4.18)$ on development initiatives.

Table 11: Overall mean score for community's perceptions on local development initiatives

\begin{tabular}{lcccc}
\hline Level & Frequency & Percentage & Mean & SD $^{*}$ \\
\hline \hline Perceptions on local development initiatives & & & 4.18 & .901 \\
Low (1.00-2.33) & 57 & 6.3 & & \\
Moderate (2.34-3.67) & 119 & 13.3 & & \\
High (3.68-5.00) & 724 & 80.4 & & \\
\hline
\end{tabular}

${ }^{\star} \mathrm{SD}=$ Standard Deviation

Table 12 exhibited the community's high level of perceptions on local development initiatives implemented by the government with the help of community members and village officials.

Table 12: Overall mean score on items of community's perceptions on local development initiatives

\begin{tabular}{lcc}
\hline Perceptions on local development initiatives & Mean & SD* $^{*}$ \\
\hline \hline Livestock / Fisheries & 4.28 & .906 \\
Small and Medium Industry (IKS) & 4.25 & .906 \\
Development of river environment & 4.22 & .909 \\
Agriculture & 4.09 & 1.10 \\
Homestay & 4.04 & 1.12 \\
Tourism (nature tourism, cultural tourism, recreation, tourism, agro-tourism, aqua tourism) & & \\
\hline${ }^{*}$ SD = Standard Deviation &
\end{tabular}

The corresponding figures in Table 13 indicated the community member's positive attitudes $(M=4.18)$ towards development initiatives.

Table 13: Overall mean score for community's attitudes towards local development initiatives

\begin{tabular}{lcccc}
\hline Level & Frequency & Percentage & Mean & $\mathrm{SD}^{*}$ \\
\hline \hline Attitudes toward local development initiatives & & & 4.49 & .572 \\
Low $(1.00-2.33)$ & 0 & 0 & & \\
Moderate $(2.34-3.67)$ & 47 & 5.2 & & \\
High $(3.68-5.00)$ & 853 & 94.8 & & \\
${ }^{*} \mathrm{SD}=$ Standard Deviation & & &
\end{tabular}

Table 14 demonstrated the community member's positive attitudes towards the idea of local development to improve their living standards within rural context.

Table 14: Overall mean score on items of community's attitudes towards local development initiatives

\begin{tabular}{lcc}
\hline Attitudes toward local development initiatives & Mean & SD* $^{*}$ \\
\hline \hline I like development & 4.52 & .569 \\
I believe that development could lead to life changes & 4.51 & .586 \\
I want local development to take place in this village & 4.49 & .594 \\
I believe that if local development did ensue, it will give a more positive impact than a negative one & 4.43 & .675 \\
$*$ SD = Standard Deviation &
\end{tabular}


Overall results regarding the local's attitudes, perceptions and expectations show that they are ready for local development. MacVaugh and Schiavone (2010) indicated how higher education and high level of literacy could bring an upward social mobility. The community leader's opinion matters as much when diffusing innovations. To greatly support local changes, local participations needed to be emphasized more by their Village Development and Security Committees (JKKK). By infusing priorities and importance of daily needs, the locals could possibly act as the designated roles as trustees during activity engagement. As the empowerment process requires a full support from the community's participation, their local mental condition needs to be trained (Sianipar et al., 2013).

\section{Conclusions}

Looking back at the statistics, the findings showed that the rural development in Malaysia still has a long way to achieve a truly empowered community. The community's attitudes towards local development scored the highest $(M=4.49)$, followed by their awareness $(M=4.40)$ and expectations $(M=4.38)$. These top three psychologically indicated the local participants were open to local development and they believed in its positive impacts and potentials to enhance their socio-economic status. Although the local participants scored high in most of the parts, their level of empowerment readiness were eminent. Moreover their partaking in decision making and involvement during community activities scored lower than the rest. Remarkably the community's independence from the government still subsist, it seemed that the Malaysian local communities were still in need of the government's help in developing their local area. Just as anticipated by Sianipar et al. (2013) in their findings, that development cannot be sustained due to community's low level of empowerment. Therefore as suggested by Sianipar et al. (2013), the role of university researchers and the government plays a major role in educating these people in order to empower them, and the process requires a full support from the community's participation (Samah and Aref, 2011).

\section{References}

Belay, K., Abebaw, D., 2004. Challenges facing agricultural extension agents: a case study from South-western Ethiopia. Afr. Develop. Rev. 16, 139-168.

Ferguson, Linda J. Transformational empowerment: Change your world from the inside out. Interbeing 2010; 4(2): 35-37.

Kasmel, A. and Andersen, Pernille T. Measurement of community empowerment in three community programs in Rapla (Estonia). International Journal of Environmental Research and Public Health 2011; 8: 799-817.

Knickel, K., Brunori, G., Rand, S., \& Proost, J. (2009). Towards a Better Conceptual Framework for Innovation Processes in Agriculture and Rural Development: From Linear Models to Systemic Approaches. The Journal of Agricultural Education and Extension, 15(February 2015), 131-146. doi:10.1080/13892240902909064

MacVaugh, J., \& Schiavone, F. (2010). Limits to the diffusion of innovation: A literature review and integrative model. European Journal of Innovation Management, 13, 197-221. doi:10.1108/14601061011040258

Nakrosis, V. (2014). Theory-based evaluation of capacity-building interventions. Evaluation, 20(1), 134-150. doi:10.1177/135638901351 7763

Ngah, I. (2010). CIPD MONOGRAPH Rural Development In Malaysia Monograph, 4 (4).

Putnam, R.D. 2000. Bowling Alone. The collapse and revival of American community. New York, NY: Simon and Schuster.

Samah, A. A., \& Aref, F., (2011). The Theoretical and Conceptual Framework and Application of Community Empowerment and Participation in Processes of Community Development in Malaysia, Journal of American Science, 2011, 7(2) 186-195.

Sianipar, C. P. M., Yudoko, G., Adhiutama, A., \& Dowaki, K. (2013). Community Empowerment through Appropriate Technology: Sustaining the Sustainable Development. Procedia Environmental Sciences, 17, 1007-1016. doi:10.1016/j.proenv.2013.02.120

Speer, Paul W., and Hughey, Joseph. Community organizing: An ecological route to empowerment and power. American Journal of Community Psychology; Oct 1995; 23(5): 729-748

Terluin, I. J. (2003). Differences in economic development in rural regions of advanced countries: an overview and critical analysis of theories. Journal of Rural Studies, 19(3), 327-344. doi:10.1016/S0743-0167(02)00071-2

WCED. Our Common Future. Oxford University Press, Oxford; 1987. 